and child in syphilis during pregnancy. Miscarriage, stillbirth and neonatal death can be averted, and infants are born apparently healthy.

Infants with congenital syphilis were given $28,600-$ 34,200 units penicillin per kilo body weight, distributed in fractions at four-hour intervals over eight days. The results as shown by clinical and serological response and by X-ray observation of the bones were very good.

Platou and associates ${ }^{8}$ have treated sixty-nine cases of infantile congenital syphilis with doses of 16,000-32,000 units penicillin per kilo distributed over seven and a half days with good symptomatic results. Of thirty-nine cases followed from four to twelve months, twenty-five remained apparently cured, nine were still sero-positive but progressing towards negativity, and five had relapsed serologically (of which two relapsed clinically). They recommend treatment with 40,000 units per kilo.

The few pregnant women I have treated for early syphilis have been given $2 \cdot 4$ million units penicillin and a standard ten-week course of neoarsphenamine and bismuth. Only one of the series has as yet come to term and she was delivered of a healthy child.

\section{Treatment Reactions}

Local pain, sometimes quite severe, may be caused by certain batches of penicillin. This may be due to impurities, and it has been noted that in such eases the penicillin powder is often a dark orange or brown colour. The therapeutic efficiency is not impaired.

Cutaneous eruptions of erythematous or urticarial type are sometimes seen during treatment but do not necessitate interruption of therapy. Shock, with pallor, sweating and rapid pulse, early in the treatment is sometimes seen. A few such cases have oceurred in our series, but treatment was never interrupted. Such reactions may possibly be due to impurities in the penicillin.

An important and almost constant feature in cases of early syphilis is a fever, sometimes high, which begins about twelve hours after the first injection and lasts for twelve to twenty-four hours. This is probably a variety of Jarisch-Herxheimer reaction, as a transitory increase in cutaneous eruptions or œdema around the chancre often occurs at the same time. In the few cases of late syphilis we have treated, this febrile reaction has not been noted. American observers have, however, noted the occurrence of therapoutic shock (for example, transverse myelitis, convulsions) in patients with late syphilis of the nervous system, and advise a cautious start with reduced doses of penicillin in such cases.

Lloyd Jones ${ }^{\theta}$ reports venous thrombosis as a complication in a series of cases treated with penicillin intravenously in large doses (up to 500,000 units).

\section{Summary and Conclusions}

Penicillin is an effective agent in the treatment of syphilis at all stages. The early results with the dosage schemes already used are encouraging, but final judgment must be deferred until a significant number of eases has been followed for a period of at least five years. There is some reason to believe that the relapse-rate in early syphilis is inversely proportional to the dosage of penicillin, so that a better cure-rate may be attained when larger doses are employed.

The use of aqueous solutions of penicillin necessitates the hospitalization of patients with syphilis. Until this difficulty is overcome, it must, for various reasons, reduce very considerably the number of patients who can have the treatment. Progress in the study of the effects of retarding media (for example, beeswax. peanut oil mixture) suggests that a method may soon be available for adequately treating syphilis with one or two injections of penicillin each day.

It appears that penicillin and the arsenicals have a synergistic action when used simultaneously. Pend. ing the results of large-scale controlled experiments, and as a means of conserving penicillin, I would advocate for routine use in early syphilis some method of combined therapy. For patients requiring a rapid complete treatment (for example, merchant seamon) the arsenoxide-penicillin treatment described above is suggested; for those who can attend as out-patients, a week's hospitalization for $2 \cdot 4$ million units penicillin, during which time can be begun a standard ten-week course of injections of neoarsphenamine and bismuth.

Every case of late syphilis deserves individual assessment; but as a basic principle, I consider that penicillin should always be followed by a long-term treatment of consolidation with a suitable arsenical and bismuth.

In conclusion, I must point out that my present advocacy of combined therapy in the treatment of syphilis does not imply that penicillin alone is incapable of producing a cure. The optimum treatment for syphilis is still undiscovered. Penicillin in larger doses or by different methods of administration may provide the answer. In the meantime, the combination of penicillin with other anti-syphilitic remedies deserves further investigation.

${ }^{1}$ Moore, Amer. J. Syph., 29 (March 1945).

${ }^{2}$ Leifer, J. Amer. Med. Assoc., 126, 67 (1944).

s Eagle, J. Amer. Med. Assoc., 553 (Oct. 28, 1944).

"Selbie and Simon, Brit. J. Exp. Path., 25, 229 (1944).

5 Nelson and Duncan, Amer. J. Syph., 29, 141 (1945).

- Stokes, Beerman and Ingraham, "Modern Clinical Syphilology" (3rd edit., 1944).

${ }^{7}$ Lenz, Ingraham, Beerman and Stokes, J. Amer. Med. Assoc., 126, 408 (1944).

s Platou, Hill, Ingraham, Goodwin, Wilkinson and Hansen, J. Amer. Med. Assoc., 127, 582 (1945).

- Lloyd Jones, paper read at Med. Soc. for Study of V.D., London (March 1945).

\section{OBITUARIES}

\section{Prof. J. T. Wilson, F.R.S.}

James Thomas Wilson, emeritus professor of anatomy in the University of Cambridge, died on September 2 at the age of eighty-four years.

An Edinburgh graduate and a pupil of Sir William Turner, Wilson went to Australia as a demonstrator of anatomy in the University of Sydney when he was twenty-six years old; three years later, independent chairs of anatomy and physiology were created and Wilson was elected as the first holder of the Challis professorship of anatomy. This position he held for the next thirty years, during which time he built up a fine department, a tradition for thoroughness in scientific investigation, and a great reputation as a university administrator of sound judgment and with an unusual breadth of vision. $\mathrm{H}_{\theta}$ was dean of the Faculty of Medicine, and, among many interests and responsibilities outside the University, he served with distinction in the Australian Intelligence Corps, being promoted honorary colonel in 1915. 
During this period, Wilson collaborated with Sir Charles Martin and, more partieularly, with Prof. J. P. Hill in research work, as a result of which many papers of fundamental importance were published on the structure and development of monotremes and marsupials. The late Sir Grafton Elliot Smith was one of his earliest pupils, and there is no doubt that Wilson's guidance and stimulating influence must have counted for much in laying the foundations for his later brilliant work.

In 1920, Wilson accepted the chair of anatomy at Cambridge. Although a comparative stranger, his outstanding abilities were quickly recognized, and he gained the respect and affection of all who worked with him in the University, and of the society of St. John's College, where he was elected to a fellowship in the same year. His work for the Cambridge Anatomy School is well known. During his fourteen years tenure of office, he enlarged and reorganized the course in anatomy for Part I of the Natural Sciences Tripos, created an excellent departmental library to which he gave a great part of his private collection of books and papers, and attracted each year a small number of students to take anatomy in Part II of the Tripos.

Wilson's scientific work was always characterized by meticulous care and thoroughness, and his papers were models in their exactness of expression and lucidity. The value of his contributions to natural science was recognized by his election into the fellowship of the Royal Society in 1909. In his later years, while at Cambridge, he spent a considerable part of his time in perfecting a technique by means of which a series of sections of large embryos could be exploited to the greatest advantage; the enthusiasm which he showed in the development of the method, and in the demonstration of his specimens to those immediately around him, was wholly characteristic; it is a great loss to embryology that but few of the many critical and original observations which he made as a result were published.

After his resignation from the chair at Cambridge in 1934, he continued to lead a full and active life; that his judgment was held in the highest esteem to the end is evidenced by the fact that this year, at the age of eighty-four, he was asked to continue his Carnegie Reports for a further year. He was the first overseas member of the Anatomical Society of Great Britain and Ireland, and he acted as its president during the years 1922-24.

This record of scientific and administrative achievement alone would place Wilson high in the ranks of great medical teachers, but his greatness and influence were more profound and far-reaching than can be indicated by a mere statement of facts. His personal example and his friendship had a marked and lasting effect on generations of students; medical men who were trained at Sydney during Wilson's time still say, when his name is mentioned, "Oh, you mean Jummy", and go on to speak of him with a spontaneous fervour delightful to hear. He had great charm of manner and a natural power of inspiring those around him; he was actuated by the highest ideals, the sincerity of which was recognized and appreciated by the members of his staff and by his students. As with his scientifie work, thoroughness and enthusiasm permeated every aspect of his teaching; he gave without stint of his time, knowledge and experience, and no one could fail to be the better man for having met and worked with him.

H. L. H. H. GREEN.
Prof. W. H. Fraenkel

THE death occurred on July 14, 1945, of Prof. Walter Fraenkel, who was living at Perth Amboy in the United States. He had been expelled from Germany early in 1939 by the Hitler Government and, after spending nearly a year at the University of Cambridge, as guest of the Metallurgical Laboratories, emigrated with his family to the United States.

Fraenkel's work covered problems of the age hardening of aluminium alloys, diffusion, segregation and crystallization and chemical reaction between metal and slag; the latter in close co-operation with R. Lorentz. Fraenkel held a professorship in Frankfurt-am-Main and there most of his research work was done, with the help of a small band of enthusiastic and devoted pupils.

Two short periods in industrial research during the First World War and in the thirties gave him an opportunity of learning about industrial problems and the industrial way of technical development.

Prof. Fraenkel was a physical chemist (trained under Bredig and Lorentz) and his approach to problems of metallurgy was always from this angle, as was the method of his teacher in this field, Tammann. He even introduced the kinetics of reaction into metallurgy in his work on the age hardening of duralumin, a problem which fascinated him during almost the whole of his research work. His studies on this subject were among the earliest scientific work done on this important theme.

I happened to be the first student who chose a subject in Prof. Fraenkel's own line of research for a thesis. The work was carried on in closest collaboration with him. He knew and watched every step and, in long and almost daily discussions, an intimate view of the man and his work was obtained, and also no small inspiration from his general attitude towards science and scientific work. His rigorous criticism of any results, be it his own or other workers, without regard to name and reputation, his modesty and his complete devotion to the cause of truth and science, were among his outstanding characteristics.

In spite of the almost pessimistic severity of his general outlook and many personal disappointments, Prof. Fraenkel possessed a keen sense of humour and a caustic wit that spared nobody, least of all himself. All his pupils and his colleagues will honour his memory as that of a man of high principles, a most capable and careful man of science and teacher and a kind and reliable friend.

E. SCHEUER.

\section{Dr. William Cramer}

William Cramer was bom in the Rhineland on June 2, 1878. After taking his Ph.D. at the University of Beriin in 1901, he worked in its department of pharmacology. There he met E. F. Bashford, and their friendship resulted in his joining the staff of the Imperial Cancer Research Fund in 1903. Thus he came to collaborate with Bashford and Murray in that pioneer work which contributed so much to our knowledge of the growth of cancer under experimental conditions.

In 1905, Cramer went to Edinburgh as lecturer in chemical physiology in Sharpey-Schafer's Department, and took the degree of D.Sc. three years later. He published "Directions for a Practical Course in Chemical Physiology" in 1912, which ran to four editions. His position as a university teacher became somewhat difficult on the outbreak of the First 